\title{
LEAF SURFACE AREA ESTIMATION IN DIFFERENT GRAPES VARIETIES USING A AM 300 LEAF AREA METER
}

Patrik BURG, Department of Horticultural Machinery, Faculty of Horticulture, Mendel University in Brno, Valtická 337, Lednice, 691 44, CZ, patrik.burg@ mendelu.cz (corresponding author)

Jana BURGOVÁ, Department of Breeding and Propagation of Horticultural Plants, Faculty of Horticulture, Mendel University in Brno, Valtická 337, Lednice, 691 44, CZ, janamok@ centrum.cz

Vladimír MA ŚŚN, Department of Horticultural Machinery, Faculty of Horticulture, Mendel University in Brno, Valtická 337, Lednice, 691 44, CZ, vladimir.masan@mendelu.cz

Miroslav VACHŨN, Mendeleum-Institute of genetics and plant breeding, Faculty of Horticulture, Mendel University in Brno, Valtická 337, Lednice, 691 44, CZ, miroslav.vachun@gmail.com

Experimental measurements focused on evaluation of grapevine leaf surface area development in nine varieties, in the viticultural conditions of South Moravia. The dynamics of leaf surface area development was measured by using a device called leaf area meter AM 300. The device operates on the principle of a scanner and the resulting values are expressed through the leaf area index - LAI. The measurements were carried out in five dates during phenophases of growth, flowering, initial development of fruits, and ripening of berries. The results show a significant differences in increase in leaf area between the evaluated varieties, especially during flowering. The size of the leaf area, depending on the year, corresponds to values between 7.615 and 13.483 square metres per hectare. The largest leaf area was reached in growth stage 8, which is ripening of fruit. The leaf area reached the largest size in the varieties Grüner Veltliner, Zweigelt, and Sauvignon, with values ranging from 20.560 to 26.481 square metres per hectare. The results suggest that a significant proportion of leaf area is also represented by lateral shoots whose size in the ripening phase, depending on variety, ranges from 33.7 to 52.9 per cent of the total leaf area.

Keywords: grapevine, lateral shoots, leaf, leaf area index, leaf area metre, viticulture

\section{INTRODUCTION}

The leaf surface area is an important factor that affects the yield of grapes and their resulting quality (Grantz and Williams, 1993). The surface area is mainly influenced by variety, nutrition, method of cut, and age of the plant. To assess the leaf surface area in practice, we often determine the index of leaf area. Measurement of leaf area index (LAI) is critical to understanding many aspects of crop development, growth, and management (Wilhelm et al., 2000).

The concept of leaf area index was at first introduced by Watson (1947) and defined as the ratio of leaf area to a given unit of land area. Martens (1993), Schultz (1995), Leblanc (2002), and Somkuwar et al. (2012) dealt with the leaf area index in each phenophase in different grape varieties at different locations.

Leaf area index is a variable representing the leaf area per unit of ground surface, where the index value of 1.0 corresponds to 10,000 square meters of leaf area per hectare of vineyard. This quantity can be calculated as the product of total leaf area per 1 annual shoot, average number of annual shoots per plant and the number of plants per 1 hectare of vineyard, divided by the area of 10,000 square meters (Jonckheere et al., 2004).

Siegfried et al. (2005) also dealt with the method of calculation. They calculated the size of the leaf area by multiplying the value of 10,000 by the number of leaves attributable to 1 linear meter and average leaf area per one leaf, divided by the width between rows.

The leaf area can also be determined by using other methods, including scanning of leaves, alpha planimeter, photometric methods, or using estimation methods or combinations of these methods.

Several authors have discussed the issues related to optimum leaf area to the amount of grapes left on the plant. Müller (2003) reported that the production of one kilogram of grapes of adequate quality requires, depending on variety and average size of leaves, 1.6 to 2.2 square metres of leaf area. Similarly Becker et al. (2007) reported that one kilogram of grapes of varieties with small grapes needs between 1.6 and 1.8 square meters of leaf area, while varieties with mediumsized to large grapes need between 2.0 and 2.2 square meters of leaf area. Spring and Zufferey (2008) state that in order

Copyright (C) 2017 The Authors. Published by Aleksandras Stulginskis University. This is an open-access article distributed under the terms of the Creative Commons Attribution License (CC-BY 4.0), which permits unrestricted use, distribution, and reproduction in any medium, provided the original author and source are credited. 
to produce one kilogram of high-quality grape 1 to 1.2 square metres of sufficiently illuminated leaf area is needed. Decisive is not the area size, but its full illumination.

Recently, practical viticulture has started to be increasingly more broadly interested in the relationships between the leaf area and the matters mentioned above. This is also evident from the viewpoint of the application of physiological processes, chemical protection of vegetation, leaf nutrition, defoliation or reduction of stocks in a given grape variety.

The aim of this paper is to assess the leaf surface area, determine the leaf area index, and compare the surface area of the main leaves and lateral shoots in selected grape varieties.

\section{MATERIALS AND METHODS}

\section{Character of the Experimental Stands}

Experimental observations and evaluations were carried out during the 2014 and 2015 growing seasons at the Rakvice Stand in the Moravian viticultural region. The lokality lies in a hot, dry region with an average annual temperature of $9-10^{\circ} \mathrm{C}$. The average rainfall is $500 \mathrm{~mm}$. Soil type is according to estimated pedological ecological unit black soil on very heavy substrates, soils are heavy with lighten topsoil horizon, with tendency to aboveground humidification of the surface profile. Stoniness is to $10 \%$.

\section{Experimental Stand Rakvice (Velké Pavlovice Sub-Region)}

The soil type at this experimental site is black, mainly loamy soil with no skeleton. The measurements of leaves surface area were carried out on the vineyard sites called "Koziperk". The vineyards are 10 years old and are grown on medium vine training, with one cane pruning; planting is $2.3 \times 0.9 \mathrm{~m}$ with grassing over one row. During the winter pruning, 10 buds were left on every shoot. The support structure consists of steel columns with a height of $1.8 \mathrm{~m}$.

\section{Character of Assessed Varieties}

The measurements of the leaf surface area were carried out on nine varieties. White varieties included Müller Thurgau (MT), Chardonnay (CH), Sauvignon Blanc (SB), Hibernal (HI), and Grüner Veltliner (GV). Red varieties included Blaufränkisch (BF), St. Laurent (SL), Zweigelt (ZW), and Pinot Noire (PN). The used rootstock differed depending on soil and climatic conditions as well as on growth intensity of the variety. On the experimental site in Rakvice, for all varieties the Kober 5BB rootstock was used. This rootstock tolerates more loamy and water-holding soils, even with higher content of active lime. Every variant is comprised by 50 shrubs.

\section{Evaluation of Surface Area of Leaves}

The measurements of the surface area of leaves were carried out annually on five dates in May, June, July, and August. The phenophases included growth, flowering, initial development of fruits (berries pea-sized, berries beginning to touch) and ripening of berries and shoots.

Leaf area meter AM 300 (ADC BioScientific Ltd., Herts, England) was used to measure the leaves surface area. This measuring instrument works on the principle of laser sensors with built-in control unit. This device measures the length, width, perimeter and ratio of the sides. Total surface area of leaves $\left(\mathrm{cm}^{2}\right)$ is automatically calculated during each scanning and the results are displayed on a display. For the actual measurements, five herbaceous shoots were randomly selected and removed from the all plants in variant. The leaf surface area and surface area of lateral shoots were then measured from the base to the top of the shoot.

The STATISTICA CZ 12 (StatSoft, Praha, CZ) program was used to evaluate evidence of the differences. The statistical methods included multidimensional statistical method, namely Cluster analysis that classifies samples into groups (clusters), so that samples belonging to the same group are more similar than objects of the other groups.

\section{RESULTS AND DISCUSSION}

Tables 1 and 2 show the resulting average values of leaf area per individual plant, expressed in square metres. These values were measured by using a destructive leaf area meter AM-300 and were also used for the determination of leaf area index (LAI).

The measured data suggest that the growth rate of leaf area was slower in the early phenophases, while faster growth occurred in the phenophases of development and ripening of fruits. The values listed in Tables 1 and 2 show an obvious difference in the intensity of development of leaf area among the evaluated varieties and dates for individual evaluations. The results show significant differences in increase in leaf area among the evaluated varieties, especially during flowering (macro phase 6). The leaf surface area, now depending on the vintage, corresponds to values between 7.615 and 13.483 square metres per hectare. These values can be obtained by multiplying the average le af area by the number of shrubs per 1 hectare vineyard according to space of plantation. Poni and Intrieri (2001) reported that he rapid development of leaf area in the period after flowering and during fruit ripening is also mainly due to the creation of leaves on lateral shoots (axes of the second order). The largest leaf surface areas were reached in growth stage 8 (ripening of fruits). The largest leaf surface areas were in the Grüner Veltliner, Zweigelt, and Sauvignon varieties. In these cases the values ranged from 20.560 to 26.481 square metres per hectare. 
Table 1. Values of leaf areas and LAI in 2014

\begin{tabular}{|c|c|c|c|c|c|c|c|c|c|c|}
\hline \multirow{2}{*}{$\begin{array}{c}\text { BBCH- } \\
\text { identification } \\
\text { keys of } \\
\text { grapevine } \\
\text { Monitored } \\
\text { Parameter }\end{array}$} & \multicolumn{2}{|c|}{$\begin{array}{l}\text { Growth stage } 1, \\
\text { Code } 16 \text { (16 leaves } \\
\text { unfolded) }\end{array}$} & \multicolumn{2}{|c|}{$\begin{array}{c}\text { Growth stage 6, } \\
\text { Code } 65 \text { (Full } \\
\text { flowering: } 50 \% \text { of } \\
\text { flowerhoods fallen) }\end{array}$} & \multicolumn{2}{|c|}{$\begin{array}{c}\text { Growth stage } 7 \text {, } \\
\text { Code } 75 \text { (Berries } \\
\text { pea-sized, bunches } \\
\text { hang) }\end{array}$} & \multicolumn{2}{|c|}{$\begin{array}{l}\text { Growth stage } 7, \\
\text { Code } 77 \text { (Berries } \\
\text { beginning to touch) }\end{array}$} & \multicolumn{2}{|c|}{$\begin{array}{l}\text { Growth stage } 8, \\
\text { Code } 81 \\
\text { (Beginning of } \\
\text { ripening: berries } \\
\text { begin to develop } \\
\text { variety-specific } \\
\text { colour) }\end{array}$} \\
\hline & $\begin{array}{c}\text { Leaf Area } \\
\left(\mathrm{m}^{2}\right)\end{array}$ & LAI & $\begin{array}{c}\text { Leaf Area } \\
\left(\mathrm{m}^{2}\right)\end{array}$ & LAI & $\begin{array}{c}\text { Leaf Area } \\
\left(\mathrm{m}^{2}\right)\end{array}$ & LAI & $\begin{array}{c}\text { Leaf Area } \\
\left(\mathrm{m}^{2}\right)\end{array}$ & LAI & $\begin{array}{c}\text { Leaf Area } \\
\left(\mathrm{m}^{2}\right)\end{array}$ & LAI \\
\hline MT & $0.71 \pm 0.06$ & 0.34 & $2.46 \pm 0.32$ & 1.19 & $3.20 \pm 0.20$ & 1.55 & $3.90 \pm 0.22$ & 1.89 & $4.28 \pm 0.27$ & 2.08 \\
\hline GV & $0.65 \pm 0.10$ & 0.31 & $2.47 \pm 0.37$ & 1.20 & $3.12 \pm 0.27$ & 1.51 & $3.92 \pm 0.53$ & 1.90 & $4.58 \pm 0.04$ & 2.22 \\
\hline HI & $0.59 \pm 0.05$ & 0.29 & $2.19 \pm 0.23$ & 1.06 & $3.05 \pm 0.18$ & 1.48 & $3.42 \pm 0.26$ & 1.66 & $3.84 \pm 0.36$ & 1.86 \\
\hline $\mathrm{CH}$ & $0.30 \pm 0.05$ & 0.17 & $1.73 \pm 0.20$ & 0.84 & $2.39 \pm 0.25$ & 1.16 & $3.16 \pm 0.26$ & 1.53 & $3.86 \pm 0.14$ & 1.87 \\
\hline SB & $0.28 \pm 0.06$ & 0.14 & $2.40 \pm 0.29$ & 1.16 & $3.07 \pm 0.21$ & 1.49 & $3.75 \pm 0.23$ & 1.82 & $4.25 \pm 0.24$ & 2.06 \\
\hline $\mathrm{BF}$ & $0.78 \pm 0.07$ & 0.38 & $2.17 \pm 0.25$ & 1.05 & $3.31 \pm 0.28$ & 1.61 & $4.14 \pm 0.07$ & 2.01 & $4.24 \pm 0.24$ & 2.06 \\
\hline SL & $0.38 \pm 0.05$ & 0.18 & $1.85 \pm 0.22$ & 0.90 & $2.85 \pm 0.20$ & 1.38 & $3.86 \pm 0.31$ & 1.87 & $4.07 \pm 0.03$ & 1.97 \\
\hline $\mathrm{ZW}$ & $0.74 \pm 0.06$ & 0.36 & $2.60 \pm 0.40$ & 1.26 & $3.48 \pm 0.22$ & 1.69 & $4.29 \pm 0.39$ & 2.08 & $4.55 \pm 0.31$ & 2.21 \\
\hline PN & $0.51 \pm 0.09$ & 0.25 & $1.57 \pm 0.26$ & 0.76 & $2.16 \pm 0.23$ & 1.05 & $3.29 \pm 0.37$ & 1.60 & $3.66 \pm 0.21$ & 1.77 \\
\hline
\end{tabular}

$\underline{\text { Table 2. Values of leaf areas and LAI in } 2015}$

\begin{tabular}{|c|c|c|c|c|c|c|c|c|c|c|}
\hline \multirow{2}{*}{$\begin{array}{c}\mathrm{BBCH} \\
\begin{array}{l}\text { Monitored } \\
\text { Parameter }\end{array}\end{array}$} & \multicolumn{2}{|c|}{$\begin{array}{c}\text { Growth stage } 1, \\
\text { Code } 15 \text { (15 leaves } \\
\text { unfolded) }\end{array}$} & \multicolumn{2}{|c|}{$\begin{array}{l}\text { Growth stage 6, } \\
\text { Code } 65 \text { (Full } \\
\text { flowering: } 50 \% \text { of } \\
\text { flowerhoods fallen) }\end{array}$} & \multicolumn{2}{|c|}{$\begin{array}{c}\text { Growth stage } 7 \text {, } \\
\text { Code } 75 \text { (Berries } \\
\text { pea-sized, bunches } \\
\text { hang) }\end{array}$} & \multicolumn{2}{|c|}{$\begin{array}{c}\text { Growth stage } 7, \\
\text { Code } 79 \text { (Majority } \\
\text { of berries touching) }\end{array}$} & \multicolumn{2}{|c|}{$\begin{array}{c}\text { Growth stage } 8, \\
\text { Code } 81 \text { (Beginning } \\
\text { of ripening: berries } \\
\text { begin to develop } \\
\text { variety-specific } \\
\text { colour) }\end{array}$} \\
\hline & $\begin{array}{l}\text { Leaf Area } \\
\text { per } 1 \text { plant } \\
\left(\mathrm{m}^{2}\right)\end{array}$ & LAI & $\begin{array}{l}\text { Leaf Area } \\
\qquad\left(\mathrm{m}^{2}\right)\end{array}$ & LAI & $\begin{array}{l}\text { Leaf Area } \\
\qquad\left(\mathrm{m}^{2}\right)\end{array}$ & LAI & $\begin{array}{l}\text { Leaf Area } \\
\left(\mathrm{m}^{2}\right)\end{array}$ & LAI & $\begin{array}{c}\text { Leaf Area } \\
\left(\mathrm{m}^{2}\right)\end{array}$ & LAI \\
\hline MT & $0.56 \pm 0.05$ & 0.27 & $2.39 \pm 0.11$ & 1.16 & $2.82 \pm 0$ & 1.37 & & 1.62 & $3.84 \pm$ & 1.86 \\
\hline GV & $0.55 \pm 0.01$ & 0.27 & $2.60 \pm 0.11$ & 1.26 & $3.68 \pm 0.31$ & 1.79 & $3.98 \pm 0.3$ & 1.93 & $4.32 \pm$ & 2.10 \\
\hline $\mathrm{HI}$ & $0.60 \pm 0.05$ & 0.29 & $2.38 \pm 0.21$ & 1.15 & $3.17 \pm 0.41$ & 1.54 & $3.57 \pm 0.40$ & 1.73 & $4.04 \pm 0.27$ & 1.96 \\
\hline $\mathrm{CH}$ & $0.38 \pm 0.10$ & 0.19 & $1.73 \pm 0.17$ & 0.84 & $2.62 \pm 0.22$ & 1.27 & $3.20 \pm 0.15$ & 1.55 & $3.77 \pm 0.12$ & 1.83 \\
\hline SB & $0.33 \pm 0.05$ & 0.16 & $2.78 \pm 0.10$ & 1.35 & $4.78 \pm 0.32$ & 2.32 & $5.17 \pm 0.28$ & 2.51 & $5.46 \pm 0.31$ & 2.65 \\
\hline $\mathrm{BF}$ & $0.73 \pm 0.09$ & 0.35 & $2.03 \pm 0.14$ & 0.98 & $2.90 \pm 0.14$ & 1.41 & $3.58 \pm 0.16$ & 1.74 & $4.04 \pm 0.10$ & 1.96 \\
\hline SL & $0.43 \pm 0.07$ & 0.21 & $2.23 \pm 0.10$ & 1.08 & $3.02 \pm 0.15$ & 1.47 & $3.77 \pm 0.11$ & 1.83 & $4.23 \pm 0.19$ & 2.05 \\
\hline ZW & $0.76 \pm 0.09$ & 0.37 & $2.56 \pm 0.22$ & 1.24 & $3.90 \pm 0.14$ & 1.89 & $4.54 \pm 0.26$ & 2.20 & $4.85 \pm 0.19$ & 2.35 \\
\hline PN & $0.48 \pm 0.05$ & 0.23 & $2.08 \pm 0.17$ & 1.01 & $2.82 \pm 0.16$ & 1.37 & $3.30 \pm 0.27$ & 1.60 & $3.56 \pm 0.24$ & 1.73 \\
\hline
\end{tabular}

Siegfried and Sacchelli (2005) also dealt with the evaluation of leaf surface area in individual phenophases. Their results show that the leaf surface area in the flowering phase ranges between 12.000 and 20.000 square metres per hectare and in the phase of fruit ripening it exceeds 23.000 square metres per hectare. Dokoozlian and Kliewer (1995) states that for a planned yield of grapes between 9.000-13.000 kg.ha-1, the bushes should have a large leaf area of 24.000-36.000 $\mathrm{m}^{2}$. The leaf area size is then in direct correlation to physiological status of grapevines (e.g. leaf size, leaf color) and fruit quality. Similarly, Marcon Filho et al. (2015), Ferrari et al. (2017) states that the balance between the fruit load and the adequately illuminated leaf area influences the quantity and quality of grape production.

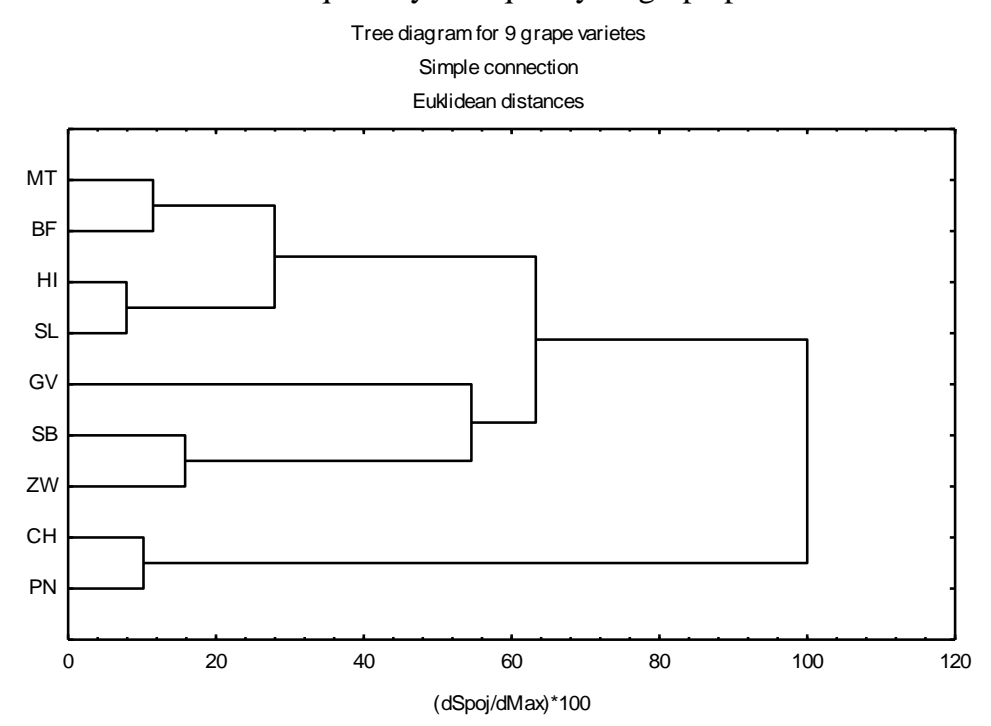

Figure 1. Dendrogram of wine grape varieties by applying the average linkage between groups and squared Euclidean distance for hierarchical cluster analysis according to the LAI. 
Eichhorn (1984) reported that in grapevine the main growth phase begins at the beginning of June, while by the end of the month the leaf area reaches its greatest development. Smith and Kliewer (1994) also reported that the largest development of leaf area occurs in the phenophase of flowering and total leaf surface area may be affected by the conditions of a given year. The difference of leaf surface area can be in the same phenophase in each year up to 30 per cent, which is also confirmed by the measured values. Spring and Zufferey (2008) show that at the beginning, leaves grow slowly, and their surface increases daily between about 200 and $600 \mathrm{~mm} 2$. During the maximum growth intensity, increase of surface the leaf blade ranges from 1000 to $2000 \mathrm{~mm} 2$. By the third growth period, the growth intensity decreases gradually to values between 300 and $500 \mathrm{~mm} 2$ per day. Their results show that the size of leaves is about 0.7 square metres per square metre of vineyard in annual shoots 0.6 metres long and 1.85 square metres in annual shoots 1.4 metres long.

Measured values are in compliance with requirements for vertically shaped leaf walls. Pavloušek (2011) states that the height of a leaf wall should be approximately 1.3 metres and the annual shoots should have at least 13 to 15 main leaves. For the quality of the grapes, the important factor is the ratio between leaf area on the annual shoot and the weight of grapes. The optimal ratio between the weight of grapes and the leaf area in our area ranges between 17 and 22 square centimetres per gram (Kraus, 1994). This means that with planned harvest of 1.5 to $2.0 \mathrm{~kg}$ of grapes from one plant the leaf area should range between 2.6 and 4.4 square meters. Comparing these data with measured values shows that in growth stage 8-ripening fruit size was sufficient leaf area for varieties with small or medium size of grapes (HI, CH, SB, $\mathrm{SL}, \mathrm{PN})$. In the fertile varieties with large grapes that requirement was fulfilled in both years, only in the variety $\mathrm{ZW}$ and GV. Problems could arise in the varieties BF and MT. Also Kliewer and Dokoozlian (2005) founded that about 0.8 to 1.2 $\mathrm{m}^{2}$ leaf area per $\mathrm{kg}$ fruit was needed to mature fruit trained to single-canopy trellis systems and 0.5 to $0.8 \mathrm{~m}^{2}$ per $\mathrm{kg}$ fruit for vines trained to divided-canopy trellis systems.

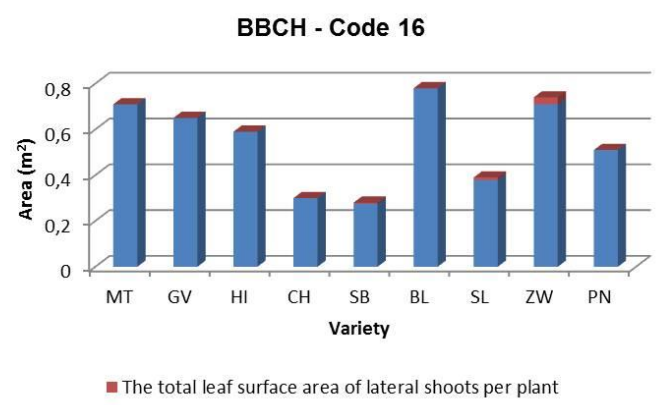

- The total leaf surface area

BBCH - Code 75

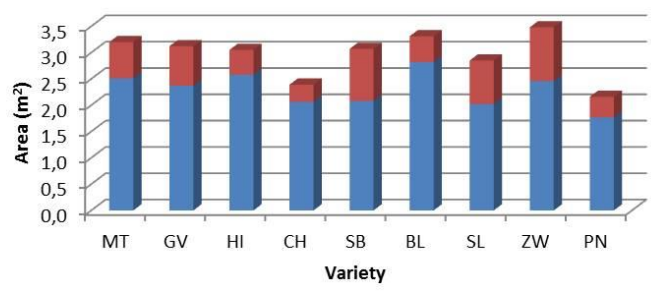

- The total leaf surface area of lateral shoots per plant - The total leaf surface area

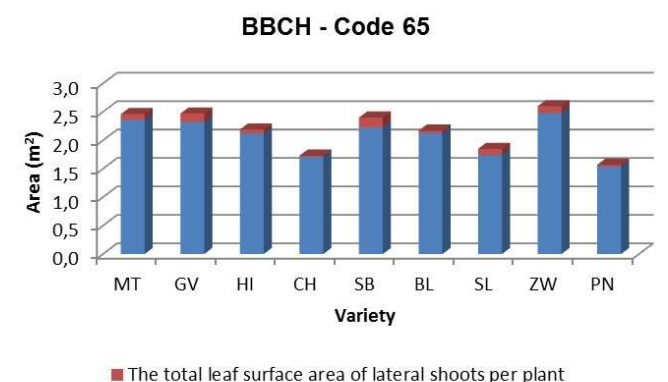

- The total leaf surface area

BBCH - Code 77

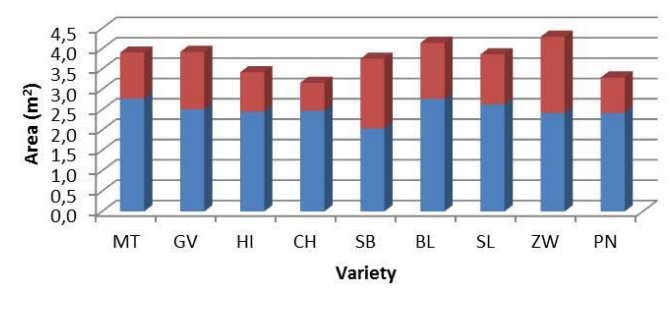

n The total leaf surface area of lateral shoots per plant m The total leaf surface area

BBCH - Code 81

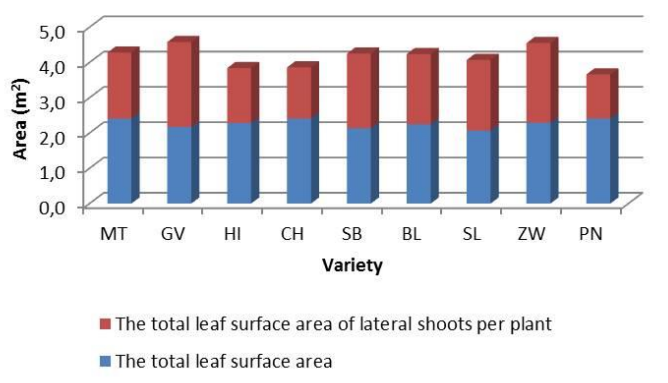

Figure 2. The total surface area of leafs and lateral shoots per plant in 2014.

The resulting values of cluster analysis shown in Figure 1 characterize the differences in the leaf surface area or leaf area index between evaluated varieties. The results indicate that in both monitored years the smallest leaf areas were recorded in Chardonnay and Pinot Noir, which are very different from other evaluated varieties. In contrast, the highest values were found in the varieties of Grüner Veltliner (GV), Zweigelt, and Sauvignon. 
The aforementioned facts may in practice mean that for the first group of varieties with enough foliage, namely, Sauvignon Blanc, Grüner Veltliner, Lemberger, St. Laurent and Zweigelt, it is possible to incorporate the defoliation step to the technological process in order to increase health condition alternatively the quality of grapes. Partial removal of leaves from the zone of grapes of these varieties will not significantly impede the ratio between the size of leaf area and grapes. However, in the second group with less foliage (Chardonnay, Pinot Noir), this could disruption this ratio occur.

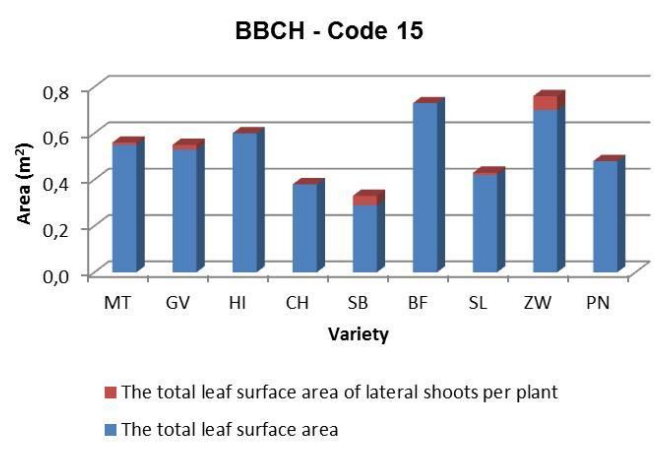

BBCH - Code 75

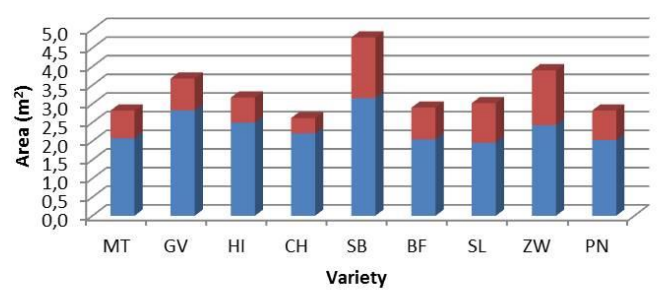

- The total leaf surface area of lateral shoots per plant - The total leaf surface area

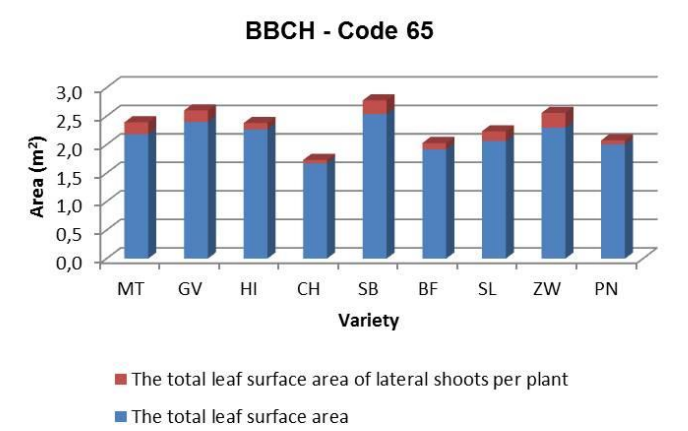

BBCH - Code 79

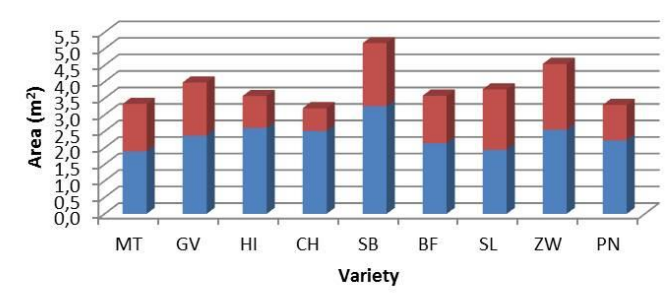

- The total leaf surface area of lateral shoots per plant

- The total leaf surface area

BBCH - Code 81

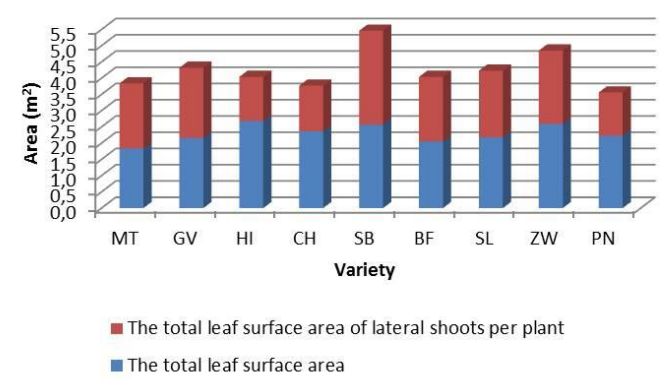

Figure 3. The total surface area of leafs and lateral shoots per plant in 2015.

Values that compare the surface area of the main leaves and lateral shoot leaves (Figures 2 and 3) using confidence interval methods constructed around arithmetic averages provide interesting results.

Lateral shoots have variable intensity of growth. Leaves on lateral shoots assimilate in a similar way as the leaves on the main shoots. Assimilates from lateral shoots from the top half of the annual shoot are transferred to the closest grapes and affect their quality parameters, such as sugar content (Schultz, 2008). Lateral shoots grow most intensively after trimming the main shoots. The intensity of their growth depends on their position on the annual shoot (Hlušek et al., 2015). The results presented in Figures 2 and 3 show that particularly in the growth stage 8 (BBCH - code 81), leaves of lateral shoots make up almost half the size of the total plant leaf surface area. The largest surface area of lateral shoots was measured in both years in the Sauvignon Blanc $\left(2.89 \mathrm{~m}^{2}\right)$, Zweigelt $\left(2.26 \mathrm{~m}^{2}\right)$ and Saint Laurent $\left(2.05 \mathrm{~m}^{2}\right)$. The presented results can also be used when breaking off lateral shoots. For example Santesteban and Royo (2006), Roland (2008) states that at the ripening stage the leaf area on lateral shoots should be at least $30 \%$ of the leaf area on the main shoots. Kliewer and Dokoozlian (2005) evaluated the ratio of leaf area on main shoots and lateral shoots for different types of trellis systems. The results of their measurements show that for the cordon shape this ratio is $2: 1$ and 3:1 for the arc shapes.

\section{CONCLUSIONS}

This experiment carried out in 2014 and 2015 was focused on the evaluation of leaf surface area in nine varieties of grapevine at the experimental site at Rakvice in South Moravia. The results can be widely used in the quality management of grapevine varieties with emphasis on the implementation of the intensity of green works. Measurement 
of leaf surface area was carried out using the leaf area meter AM 300. It showed that among the evaluated varieties, there were differences in leaf surface area, which was the largest in the Zweigelt, Sauvignon, and Grüner Veltliner varieties. In this case the values were from 20,000 to 26,000 square metres per hectare. In contrast, the smallest leaf surface area for the reporting period was found in the varieties of Pinot Noir, Chardonnay, and Hibernal, fluctuating between 17,000 and 19,000 square metres per hectare.

The leaf surface area is also related to values of lateral shoot leaves. The largest surface area of lateral shoots was measured in both years in Sauvignon Blanc $\left(2.89 \mathrm{~m}^{2}\right)$, Zweigelt $\left(2.26 \mathrm{~m}^{2}\right)$ and Saint Laurent $\left(2.05 \mathrm{~m}^{2}\right)$. The greatest development of lateral shoot leaf area occurs at the phase of fruit ripening. Depending on the variety, their size makes up 33.7 to 52.9 per cent of the total leaf area per plant. These facts may in practice mean that for varieties with enough foliage, namely Müller Thurgau, Sauvignon Blanc, Grüner Veltliner, Blaufränkisch, St. Laurent, and Zweigelt, it is possible to incorporate the defoliation operation to the technological process to increase the quality of grapes. In the second group with less foliage, namely Chardonnay and Pinot Noir, in order to achieve the highest quality of grapes, rather a reduction of harvest can be recommended or to carry out defoliation or breaking off lateral shoots considering a thorough knowledge of local conditions.

\section{REFERENCES}

1. Dokoozlian, N. K., Kliewer, W.M. 1995. The light environment with grapevine canopies. I. Description and seasonal changes during fruit development. American Journal of Enology and Viticulture, Vol. 46, pp. 209-218.

2. Eichhorn, K. W. 1984. The development of the leaf area of grapevine (in German). Der Deutsche Weinbau 36, pp. $1532-1537$.

3. Grantz, D. A., Williams, L. E. 1993. An empirical protocol for indirect measurement of leaf area index in grape (Vitis vinifera L.). Horticultural Science, Vol. 28, pp. 777-779.

4. Ferrari, V., Disegna, E., Dellacassa, E., Coniberti, A. 2017. Influence of timing and intensity of fruit zone leaf removal and kaolin applications on bunch rot control and quality improvement of Sauvignon blanc grapes, and wines, in a temperate humid climate. Scientia Horticulturae, Vol. 223, pp. 62-71. https://doi.org/10.1016/j.scienta.2017.05.034

5. Hlušek, J., Baroň, M., Burg, P. 2015. Grapevine [in Czech]. 1. Edition, Profi-press, Prague, Czech Republic.

6. Jonckheere, S., Fleck, K., Nackerts, B., Muys, P., Coppin, M. 2004. Review of methods for in situ leaf area index determination. Part I. Theories, sensors and hemispherical photography. Agricultural and Forest Meteorology, Vol. 121, pp. 19-35. https://doi.org/10.1016/j.agrformet.2003.08.027

7. Kliewer, W. M., Dokoozlian, N. K. 2005. Leaf Area/Crop Weight Ratios of Grapevines: Influence on Fruit Composition and Wine Quality. American Journal of Enology and Viticulture, Voil. 56, pp. 170-181.

8. Kraus, V. 1994. Viticulture [in Czech]. 1. Edition, VŠZ, Prague, Czech Republic.

9. Kraus, V. 1983. Biological basics of grapevine agrotechnic [in Czech]. 1. Edition, State Pedagogical Publishing House, Prague, Czech Republic.

10. Leblanc, S. G., Fernandes, R., Chen, J. M. 2002. Recent advancements in optical field leaf area index, foliage heterogeneity, and foliage angular distribution measurements. In: Proceedings of IGARSS 2002, Toronto, Canada, pp. $2902-2904$. https://doi.org/10.4095/219868

11. Lorenz, D., Eichhorn, K. W., Blei-Holder, H., Klose, R., Meier, U. 1994. The development of phenological stages of grapevine Vitis vinifera L. ssp. Vinifera (in German). Codierung und Beschreibung nach der erweiterten BBCH-Skala. Wein-Wissenschaft, Vol. 49, pp. 66-70.

12. Marcon Filho, J. L., Hipólito, J. S., Macedo, T. A., Kretzschmar, A. A., Rufato, L. 2015. Raleio de cachos sobre o potencial enológico da uva 'Cabernet Franc' em duas safras. Ciência Rural, Vol. 45, pp. 2150-2156. https://doi.org/10.1590/0103$\underline{8478 \mathrm{cr} 20140995}$

13. Martens, S. N., Ustin, S. L., Rousseau, R. A. 1993. Estimation of tree canopy leaf-area index by gap fraction analysis. Forest Ecology and Management, Vol. 61, pp. 1-108. https://doi.org/10.1016/0378-1127(93)90192-P

14. Müller, E. 2003. Riesling-grape systems, trellis design, green works (in German). Die Winzer Zeitung, Vol. 7, pp. $542-547$.

15. Ollat N., Fermaud M., Tandonnet J. P., Neveux M. 1998. Evaluation of an indirect method for leaf area index determination in the vineyard: combined effects of cultivar, year and training system. Vitis 37, pp. 73-78.

16. Pavloušek, P. 2007. Quality management in viticulture (in Czech). Habilitation work, Faculty of Horticulture, Mendel University in Brno.

17. Patakas A., Noitsakis B. 1999. An indirect method of estimating leaf area index in cordon trained spur pruned grapevines. Scientia Horticulturae, Vol. 80, pp. 299-305. https://doi.org/10.1016/S0304-4238(98)00244-1

18. Poni, S., Intrieri, C. 2001. Grapevine photosynthesis: Effects linked to light radiation and leaf age. Advances in Horticultural Science, Vol. 15, pp. 5-15.

19. Ronald, S.J., 2008. Wine Science Principles and Applications. 3rd ed., 4, pp.120-140.

20. Santesteban, L.G., Royo, J.B. 2006. Water status, leaf area and fruit load influence on berry weight and sugar accumulation ov cv. 'Tempranillo' under semiarid conditions. Scientia Horticulturae, Vol. 109, pp. 60-65. https://doi.org/10.1016/j.scienta.2006.03.003

21. Schultz, H. R. 1992. An empirical model for the simulation of leaf appearance and leaf area development of primary shoots of several grapevine (Vitis vinifera L.) canopy-systems. Scientia Horticulturae, Vol. 52, pp. 179-200. https://doi.org/10.1016/0304$\underline{4238(92) 90020-\mathrm{D}}$ 
22. Schultz, H. R. 1995. Grape canopy structure, light microclimate and photosynthesis. I. A two dimensional model of the spatial distribution of surface area densities and leaf ages in two canopy systems. Vitis, Vol. 34, pp. 211-215.

23. Schultz, H. R. 2008. European Challenges. Proceedings from 13th Australian Wine Industry Tech. Conference, Adelaide, Australien, pp. 33-36.

24. Siegfried W., Sachelli, M., Viret, O., Wohlhauser, R., Raisigl, U., Huber, B., Ipach, R., Bäcker, G. 2005. Leaf area-related dosage of pesticides in viticulture (in German). Schweizerische Zeitschrift für Obst- und Weinbau, Vol. 4, pp.13-16.

25. Smith R. J., Kliewer W. M. 1994. Estimation of Thompson Seedless Grapevine Leaf Area. Department of Viticulture and Enology, University of California. American Journal of Enology and Viticulture, Vol. 35, pp. 16-22.

26. Spring J. L., Zufferey, V. 2008. Vegetative development and nitrogen supply of the vine (in German). Schweizerische Zeitschrift für Obst- und Weinbau, Vol. 15, pp. 4-6.

27. Watson, D. J. 1947. Comparative physiological studies in the growth of field crops.I. Variation in net assimilation rate and leaf area between species and varieties, and within and between years. Annals of Botany, Vol. 11, pp. 41-76. https://doi.org/10.1093/oxfordjournals.aob.a083148

28. Welles, J. M. 1990. Some indirect methods of estimating canopy structure. Remote sensing reviews, Vol. 5, pp. 31-43. https://doi.org/10.1080/02757259009532120 